\title{
CÉLINE TORRENT, Le poétique instinct à travers la danse
}

\section{Luana Doni}

\section{(2) OpenEdition \\ Journals}

\section{Edizione digitale}

URL: https://journals.openedition.org/studifrancesi/44299

DOI: 10.4000/studifrancesi.44299

ISSN: 2427-5856

\section{Editore}

Rosenberg \& Sellier

\section{Edizione cartacea}

Data di pubblicazione: 1 juin 2021

Paginazione: 263-264

ISSN: 0039-2944

\section{Notizia bibliografica digitale}

Luana Doni, «CÉLINE TORRENT, Le poétique instinct à travers la danse», Studi Francesi [Online], 193 (LXV | I) I 2021, online dal 01 juillet 2021, consultato il 14 octobre 2022. URL: http://journals.openedition.org/ studifrancesi/44299 ; DOI: https://doi.org/10.4000/studifrancesi.44299

Questo documento è stato generato automaticamente il 14 octobre 2022.

\section{(c)}

Creative Commons - Attribuzione - Non commerciale - Non opere derivate 4.0 Internazionale - CC BYNC-ND 4.0

https://creativecommons.org/licenses/by-nc-nd/4.0/ 


\title{
CÉLINE TORRENT, Le poétique instinct à travers la danse
}

\author{
Luana Doni
}

\section{NOTIZIA}

CÉLINE TORRENT, Le poétique instinct à travers la danse, Paris, L'Harmattan, 2019, 593 pp.

1 Il presente studio intende indagare l'enigma intorno al quale si articola l'espressione di Mallarmé "poétique instinct», usata per sottolineare il legame tra poesia e danza.

2 La danza e la letteratura risultano essere, secondo l'indagine di Céline TORRENT, due discipline aprioristicamente incompatibili data la natura stessa del loro costituirsi: la danza come rappresentazione dell'effimero, la letteratura come una traccia indelebile sulla carta.

3 A partire dagli anni Novanta del Novecento, la ricerca scientifica, grazie anche alla nascita di campi di studio come le Arti dello Spettacolo, ha potuto avvicinarsi allo studio della danza da un punto di vista letterario e filosofico.

4 Tale avvicinamento è dovuto, in modo particolare, al ritrovato dialogo, a partire dalla fine del xx secolo e l'inizio del xxI, tra scrittori e danzatori; a testimonianza del fatto, i lavori di Guy Ducrey e Hélène Laplace-Claverie, che decidono di risalire alle origini del legame tra danza e scrittura per arrivare a dimostrare l'influenza implicita della danza contemporanea sugli autori del xx secolo, e aprono la strada a una serie di convegni e pubblicazioni concentrate sulla relazione tra le due discipline.

5 La prospettiva adottata dall'autrice è quella di considerare la danza come scrittura poetica a tutti gli effetti attraverso la visione di sei poeti simbolo: Stéphane Mallarmé, Pascal Quignard, Jean-Michel Maulpoix, Paul Valéry, André Velter e René Char.

6 La prima sezione del volume («La poésie en quête d'elle-même tournée vers la danse fin xixe/début xxe siècle: Mallarmé et Valéry», pp. 51-195), si concentra sulla rivoluzione del linguaggio poetico alla fine del XIX secolo. Mallarmé, che ha teorizzato la crisi della 
forma poetica nella modernità, ha utilizzato proprio la danza come paradigma al fine di rimettere in discussione i dogmi della scrittura.

7 Ecco che gli scrittori smettono di scrivere per il balletto e cominciano invece a scrivere attraverso di lui, alla ricerco dell'oggetto poetico; non a caso, la figura di Salomé gode di un enorme successo proprio nella letteratura di fine Ottocento poiché coniuga il mistero della donna al mistero della danza. Una visione, questa, assai riduttiva secondo la poetica di Mallarmé, lontana da qualsivoglia affiancamento tra la danzatrice e la cortigiana.

Per Mallarmé, a differenza di ciò che sosteneva il naturalista Zola, è la danzatrice a mettere a nudo la danza e la sua poetica; la ballerina di Mallarmé non è svestita ma nuda nel senso di libera nella danza. Quest'idea di "messa a nudo" della danza agisce da specchio riflettente per il poeta che elabora lo stesso concetto di nudità ma nella scrittura.

9 La nozione di "scrittura corporale" è usata da Hugues Marchal proprio per definire la poetica di Mallarmé, nella quale il corpo del poeta e quello del lettore si esibiscono in una coreografia esattamente come accade nel balletto. L'autrice prosegue infatti con l'esemplificazione pragmatica del concetto di scrittura corporale in Mallarmé e lo fa tramite l'analisi del poema incompiuto Hérodiade attraverso lo sguardo della danzatrice Wilfride Piollet.

Per Paul Valéry, invece, la danza e la scrittura si legano secondo due processi differenti: da un lato l'impossibilità di dare una definizione della danza che non sia astratta; dall'altro la realizzazione concreta del suo legame con la scrittura nei due melodrammi, Amphion e Sémiramis.

11 L'ultima parte della prima sezione del volume cerca di analizzare la maniera in cui Valéry mette in pratica la nozione mallarmeana di "scrittura corporale", attraverso la concezione della danza come paradigma del gesto creatore, riportando l'atto di scrittura verso la sua dimensione fisica.

Nella seconda sezione del volume poi («La danse se découvrant «écriture corporelle»: vers la notion de danse-contempoïein», pp. 199-358) l'autrice mostra come la danza stessa si scopre scrittura corporale verso la fine del xix secolo.

Nel testo Poétique de la danse contemporaine, Laurence Louppe spiega come, verso la fine del xIX secolo, la danza conosca un vero e proprio periodo di rinnovamento causato dalla presa di coscienza della propria possibilità di creazione, senza bisogno del supporto di un libretto. La danza si assume come scrittura in divenire, poïegraphique, motivo per cui i poeti cercano in essa la propria ispirazione.

Nella parte finale della sezione, Torrent cerca di dare una definizione di danzacontempoïein, mostrando come, in realtà, si tratti di un vero e proprio procedimento di tipo poetico sia da parte del coreografo, sia da parte del danzatore, capace di crearsi esattamente come si crea una poesia, nell'attimo presente, nell'azione e contemporaneamente ad essa. L'esempio di Wilfride Piollet è riportato a testimoniare il fatto che una tecnica di balletto che attinga all'immaginario poetico permette al danzatore non solo di creare ma di crearsi come poesia corporale.

La terza e ultima sezione del volume («"Poétique instinct” et danse à travers le "renouveau lyrique" au tournant des $\mathrm{XX}^{\mathrm{e}}$ et XXI ${ }^{\mathrm{e}}$ siècles. "L'instinct de ciel", des cordes de la lyre au corps-lyre», pp. 361-498) si concentra sui rapporti tra danza e scrittura nel 
xx secolo, alla ricerca delle ragioni per le quali la letteratura decide di ritornare alla danza e di scrivere nuovamente per il corpo in movimento.

16 Il lavoro si conclude con l'idea di un nuovo inizio, quello che vede nel gesto ciò che precede l'atto di scrittura; la poesia si percepisce attraverso la danza come la relazione tra l'io e il mondo attraverso il corpo. 